\title{
Association between -308 G/A TNF- $\alpha$ Polymorphism and Appendicular Skeletal Muscle Mass Index as a Marker of Sarcopenia in Normal Weight Obese Syndrome
}

\author{
L. Di Renzo, ${ }^{1}$ F. Sarlo, ${ }^{1}$ L. Petramala, ${ }^{1}$ L. Iacopino, ${ }^{1}$ G. Monteleone, ${ }^{2}$ \\ C. Colica, ${ }^{3}$ and A. De Lorenzo ${ }^{1,4}$ \\ ${ }^{1}$ Division of Clinical Nutrition and Nutrigenomic, Department of Biomedicine and Prevention, \\ University of Tor Vergata, Via Montpellier 1, 00133 Rome, Italy \\ ${ }^{2}$ Department of Biomedicine and Prevention, University of Tor Vergata, Via Montpellier 1, 00133 Rome, Italy \\ ${ }^{3}$ CNR, ISN UOS of Pharmacology, Department of Pharmacology, University Magna Graecia, Roccelletta di Borgia, \\ 88050 Catanzaro, Italy \\ ${ }^{4}$ I.N.Di.M., National Institute for Mediterranean Diet and Nutrigenomic, 870320 Amantea, Italy
}

Correspondence should be addressed to A. De Lorenzo; delorenzo@uniroma2.it

Received 14 June 2013; Accepted 30 September 2013

Academic Editor: George Perry

Copyright (C) 2013 L. Di Renzo et al. This is an open access article distributed under the Creative Commons Attribution License, which permits unrestricted use, distribution, and reproduction in any medium, provided the original work is properly cited.

Background and Aim. Normal weight obese (NWO) syndrome is characterized by normal body mass index (BMI), but high amount of fat mass and reduced lean mass. We evaluated allelic frequency of the G/A -308 TNF- $\alpha$ polymorphism and prevalence of sarcopenia in NWO. Methods. We enrolled 120 Italian healthy women, distinguished into 3 groups: normal weight (NW); NWO, and preobese-obese (PreOB/OB) and evaluated anthropometric parameters, body composition by dual X-ray absorptiometry, blood tests, and genotyping of G/A -308 TNF- $\alpha$ polymorphism. Results. We found a positive association between sarcopenic obesity and -308 TNF- $\alpha$ polymorphism. All obese women were sarcopenic and were no carrier of mutation (G/G). Among all G/G, NWO showed significant differences in lean mass and total body lean mass (TBLean) with respect to NW and PreOB/OB $(P<0.001)$. Regarding appendicular skeletal muscle mass index values, $4.21 \%$ of $\mathrm{NW}$ were sarcopenic $(50 \% \mathrm{G} / \mathrm{G}$ and $50 \% \mathrm{G} / \mathrm{A})$; the same percentage was observed in NWO subjects (100\% G/G). Moreover, $2.10 \%$ of PreOB/OB were sarcopenic and all were G/G. Conclusion. Our study suggests that TNF- $\alpha$ polymorphism contributes to sarcopenic obesity susceptibility, in association with body composition. This is the first study that shows the importance of TNF- $\alpha$ polymorphism to determine TBLean variation in NWO syndrome.

\section{Introduction}

Sarcopenia is defined according to the European consensus as a condition that involves a loss of muscle mass and declining strength and/or physical performance and has profound physiologic and clinical consequences, including but not limited to impaired protein turnover, mobility loss, osteoporosis, increased fracture risk, dyslipidemia, insulin resistance, overall frailty, and increased mortality.

A necessary condition for a diagnosis of sarcopenia is therefore the extent of muscle mass loss that should be considered significant $[1,2]$.
The combination of sarcopenia and obesity [3], defined as sarcopenic obesity, is an important public health that induces fragility in the elderly, and it is associated with functional limitations and increased mortality $[4,5]$.

In order to avoid the risk of sarcopenic obesity in the elderly and to prevent in the young population, the diagnosis of obesity requires the utilization of various methods, including body composition evaluation, metabolic, functional, and a genetic approach [6-9].

A number of candidate genes for obesity [10] and osteoporosis have been identified [11], but the genetic basis of sarcopenia is still largely unknown. 
Greater loss of muscle mass leading to sarcopenic obesity in women occurs increasingly with age. Body mass index (BMI) does not acknowledge this factor, exacerbating misclassifications [12]. DXA-derived total body lean mass (TBLean) measures can reflect both muscle mass and muscle strength, providing a reliable measure for assessment of sarcopenia and obesity $[13,14]$.

De Lorenzo et al. have identified the normal weight obese (NWO) syndrome, characterized by normal body weight and BMI, but high total body fat mass (TBFat) accumulation (>30\%) accompanied by TBLean deficiency [15] and high level of atherogenic indices and oxidative stress $[16,17]$. The frequency of NWO syndrome in the worldwide population is near to $10 \%$, and the prevalence is higher in women than in men [18-21].

NWO had a higher prevalence of metabolic syndrome, dyslipidemia, hypertension (men), CVD (women), and a 2.2fold increased risk of CVD mortality (women) compared with those with low TBFat [22]. Early inflammation and genetic predisposition characterizes the syndrome [7, 23-25]. Moreover, a cross-talk between skeletal muscle and adipose tissue in NWO syndrome has been supposed and linked with the control of body weight, both fat stores and muscle mass.

Tumor necrosis factor alpha (TNF- $\alpha$ ) could play a decisive role in the proposed cross-talk between adipose tissue and skeletal muscle [26], with development of muscular abnormalities resulting in a loss of skeletal muscle mass and function. TNF- $\alpha$ is a cytokine implicated in the metabolic disturbances of chronic inflammation with its biological actions including induction of insulin resistance, anorexia, and weight loss. It is overexpressed in adipose tissue, which is both a source of and a target for TNF- $\alpha$ [27].

TNF- $\alpha$ human gene is located on the short arm of chromosome 6 [28]. The G/A -308 polymorphism in the TNF$\alpha$ promoter gene increases transcriptional activation of the TNF- $\alpha$ gene [29].

Given the clinical significance of sarcopenic obesity, the purpose of the present study was to investigate the allelic frequency of the G/A -308 polymorphism in the TNF- $\alpha$ promoter gene and to determine whether this polymorphism is associated with appendicular skeletal muscle mass index (ASMMI) in NWO Italian population.

We comprehensively analyzed TBFat, TBLean, anthropometric, and biochemical and cardiovascular risk factors parameters in TNF- $\alpha$ gene association study in NWO subjects.

\section{Materials and Methods}

2.1. Subjects. The study was conducted on a sample of 120 Italian Caucasian women (aged 20 to 60), recruited from ongoing studies at the University of Rome Tor Vergata (Italy), from June 2012 to January 2013. A completed screening of anthropometry and body composition was assessed using standardized equipment.

Exclusion criteria were exposure to hormonal treatment or development of secondary obesity due to endocrine diseases or serious intercurrent illness. Subjects with a history or symptoms of coronary artery, cerebrovascular or peripheral artery disease, heart failure, renal or hepatic diseases, alcohol abuse, or smoking were excluded, as well as those with established type 2 diabetes. It was ascertained that none were taking lipid-lowering or antidiabetic medications, insulin, nitro derivatives, systemic corticosteroids, or any hormonal contraception. A completed screening of anthropometry and body composition was assessed.

The subjects were categorized into 3 different groups according to BMI and the percentage of TBFat (PBF): (1) normal weight (NW) women having a BMI $<25 \mathrm{~kg} / \mathrm{m}^{2}$, PBF $<30 \%$; (2) NWO women with BMI $<25 \mathrm{~kg} / \mathrm{m}^{2}, \mathrm{PBF}>30 \%$ [15]. NWO women had regular 28-day menstrual cycles; (3) preobese-obese $(\mathrm{PreOB} / \mathrm{OB})$ women with a $\mathrm{BMI}>25 \mathrm{~kg} / \mathrm{m}^{2}$, $\mathrm{PBF}>30 \%$.

Study design was clearly written in lay person language and provided to each study subject. A written informed consent was obtained from each patient and the study protocol conforms to the ethical guidelines of the Declaration of Helsinki. The collection of serum and DNA as well as the experiments was approved, and the study was conducted according to the guidelines of the "Tor Vergata" University Medical Ethical Committee, Rome, Italy.

2.2. Anthropometric Measurements. Anthropometric parameters for all participants were performed by trained personnel (body weight, height, hip, and waist circumferences), with participants wearing only light underwear and without shoes.

Waist and hip measures were taken using a flexible steel metric tape to the nearest $0.5 \mathrm{~cm}$, with subjects standing with arms relaxed by their side and balanced on both feet. The tape was held tight to the skin but without compression of tissue. Hip circumference was taken at the greatest posterior protuberance of the buttocks. Waist circumference was measured just above the iliac crest. Body weight $(\mathrm{kg})$ was measured to the nearest $0.1 \mathrm{~kg}$, using a balance scale (Invernizzi, Rome, Italy). Height (m) was measured using a stadiometry to the nearest $0.1 \mathrm{~cm}$ (Invernizzi, Rome, Italy). Body mass index (BMI) was calculated as body weight (in kilograms) divided body height (in meters) squared.

2.3. Dual X-ray Absorptiometry (DXA). The total body composition was assessed by DXA (iDXA, G.E. Medical Systems, WI, USA), according to the previously described procedure [30]. The CV value (S.D./mean) for repeated measurements is $1.0-2.2 \%$ in our laboratory depending on application.

PBF was calculated as TBFat mass divided by total mass of tissues (TBFat + TBLean + Bone Mass $) \times 100$. ASMMI was calculated as follows $=$ (Appendicular skeletal muscle mass/height ${ }^{2}$; women were defined sarcopenic with ASMMI $<5.47 \mathrm{~kg} / \mathrm{m}^{2}$ ) [1].

2.4. Analysis of Blood Samples. Blood samples were collected into sterile tubes containing EDTA (Vacutainer). All materials were immediately placed in ice and plasma was stored at $-70^{\circ} \mathrm{C}$, for cytokine determinations. Analyses were carried out according to the standard techniques by the accredited 
Clinical Chemical Laboratories of the "Tor Vergata" Polyclinic (PTV) of Rome, Italy.

Insulin resistance was determined by homeostasis model assessment-insulin resistance $(\mathrm{HOMA}-\mathrm{IR})=[$ (fasting glucose $(\mathrm{mmol} / \mathrm{L}) \times$ fasting insulin $(\mu \mathrm{IU} / \mathrm{mL})) / 22.5]$.

Atherogenic indices were calculated as follows: total cholesterol (mg/dL)/HDL cholesterol (mg/dL) (normal value $<5$ for men and $<4.5$ for women), LDL cholesterol (mg/dL)/ HDL cholesterol $(\mathrm{mg} / \mathrm{dL}$ ) (normal value $<3.5$ for men and $<3$ for women), and $\log$ (triglycerides $(\mathrm{mg} / \mathrm{dL}) / \mathrm{HDL}(\mathrm{mg} / \mathrm{dL})$ ) (normal value $<0.5$ ).

2.5. Cytokine Assay. Blood levels of TNF- $\alpha$ cytokine were quantified with an ELISA assay (Mabtech, Italy) according to the manufacturer's instruction (lower limit of TNF- $\alpha$ detection was $1.6 \mathrm{pg} / \mathrm{mL}$ ).

\subsection{Genetic Analysis}

TNF- $\alpha$ Polymorphism. Sequencing of the $5^{\prime}$-region $(-595$ to +390 ) of the human TNF- $\alpha$ gene revealed a $G$ to a $A$ transition polymorphism at position -308 . Digestion with NcoI enzyme, revealed the presence of two alleles: allele A1 gives two fragments of $87 \mathrm{bp}$ and $20 \mathrm{bp}$, allele 2 a single $107 \mathrm{bp}$ fragment. Amplification of $100 \mathrm{ng}$ of genomic DNA was performed using initial denaturation at $94^{\circ} \mathrm{C}$ for $4 \mathrm{~min}$ followed by 30 cycles of $95^{\circ} \mathrm{C}$ for $1 \mathrm{~min}, 60^{\circ} \mathrm{C}$ for $1 \mathrm{~min}$, and $72^{\circ} \mathrm{C}$ for $1 \mathrm{~min}$ with a final extension at $72^{\circ} \mathrm{C}$ for $10 \mathrm{~min}$. The buffer for PCR reaction contained $2.5 \mathrm{mM} \mathrm{MgCl}_{2}$, $9.9 \mathrm{mM}$ Tris- $\mathrm{HCl}$ (pH 8.8), $50 \mathrm{mM} \mathrm{KCl,} \mathrm{0.1 \%} \mathrm{Triton \_ X} \mathrm{100,}$ $0.200 \mu \mathrm{M}$ deoxyribonucleotide triphosphate (dNTPs), $1 \mathrm{U}$ of Taq DNA polymerase, and $0.2 \mu \mathrm{M}$ of each primer. The primer sequences are $5^{\prime}$-AGGCAATAGGTTTTGAGGGCCAT- ${ }^{\prime}$ and $5^{\prime}$-TCCTCCCTGCTCCGATTCCG-3'.

The amplified product was digested with NcoI and analysed on agarose gel and visualized under UV light after ethidium bromide staining [31].

2.7. Statistical Analysis. Data are presented as group means \pm standard deviations (SD). The Mann-Whitney test was used to assess the significance among the groups. The level of significance was fixed at $P \leq 0.05$ for all the procedures. Statistical analysis was performed using a computer software package (SPSS for Windows, version 13.0; SPSS, Chicago, IL).

\section{Results}

One hundred twenty Caucasian Italian women gave informed consent and were enrolled: 95 subjects were eligible for the study design according to inclusion criteria, with mean age of $33.61 \pm 12.01$ years and mean BMI of $26.46 \pm 5.64 \mathrm{Kg} / \mathrm{m}^{2}$. Characterization of the nutritional status by BMI revealed that $3.16 \%(n=3)$ were underweight, $45.26 \%(n=$ 43) were normal weight (eutrophic), 26.32\% $(n=25)$ were overweight, and $25.26 \%(n=24)$ were obese. None of the subjects classified as obese by BMI were sarcopenic, according to ASMMI. When all women were classified by
TABLE 1: Prevalence of sarcopenic obesity distinguished by BMI or DXA.

\begin{tabular}{lcccc}
\hline Sarcopenia & \multicolumn{2}{c}{ BMI } & \multicolumn{2}{c}{ DXA } \\
& $\begin{array}{c}\text { Eutrophic } \\
(n .71)\end{array}$ & $\begin{array}{c}\text { Obese } \\
(n .24)\end{array}$ & $\begin{array}{c}\text { Eutrophic } \\
(n .17)\end{array}$ & $\begin{array}{c}\text { Obese } \\
(n .78)\end{array}$ \\
\hline $\begin{array}{l}\text { Relative ASMMI } \\
\mathrm{kg} / \mathrm{m}^{2}<5.5\end{array}$ & & & & \\
$\quad n$. & 7 & 0 & 4 & 6 \\
$\quad \%$ & 9.85 & 0 & 23.53 & 7.69 \\
\hline $\begin{array}{l}\text { Relative ASMMI } \\
\mathrm{kg} / \mathrm{m}^{2}>5.5\end{array}$ & & & & \\
$n$. & 64 & 24 & 13 & 72 \\
$\%$ & 90.15 & 100 & 76.47 & 92.31 \\
\hline
\end{tabular}

ASMMI: appendicular skeletal muscle mass index; BMI: body mass index; DXA: dual-energy X-ray absorptiometry.

DXA, the majority $(82.10 \%, n=78)$ were classified as obese, and $7.69 \%(n=6)$ of them presented sarcopenic obesity.

Significant difference in the diagnosis of obesity between $\mathrm{BMI}$ and $\mathrm{PBF}$ was observed with an error percentage of 30.39\% $(P<0.005)$.

Characterization of sarcopenic obesity, determined by BMI or DXA, and the relative ASMMI are presented in Table 1. No association between sarcopenia and BMI was found. There was no association with sarcopenic obesity independent of body composition determined by DXA.

The baseline characteristics of subjects, classified according to their genotypes, were shown in Table 2. All subjects were successfully genotyped for the G/A -308 TNF$\alpha$ polymorphism, distinguishing in wild type homozygote $(\mathrm{G} / \mathrm{G})$, heterozygosis (G/A), and mutant homozygote (A/A) genotypes. No carrier homozygote A/A was found. A total of 70 subjects $(73.68 \%)$ defined as carrier (-) group had the G/G -308 TNF- $\alpha$ genotype with an average age of $33.64 \pm$ 12.05 years. 25 subjects $(26.32 \%)$ defined as carrier (+) group had the G/A -308 TNF- $\alpha$ genotype with an average age of $33.24 \pm 12.29$ years, without statistical differences in the mean age. Allelic frequency of the A substitution -308 was $27.36 \%$. The observed genotype frequencies in our sample were in the Hardy-Weinberg equilibrium. No statistical differences were detected.

There was a positive association between sarcopenia, sarcopenic obesity, and -308 TNF- $\alpha$ genotype; hence all the obese women with sarcopenia present sarcopenic obesity and were carrier (-) (data not show).

Table 3 shows biochemical parameters and cardiovascular risk factors according to genotype. The carrier (+) group did not have a worse metabolic profile than carrier (-) group. Only hs-CRP $(\mu \mathrm{g} / \mathrm{dL})$ values were significantly different between the two groups $(0.73 \pm 1.78 \mu \mathrm{g} / \mathrm{dL}$ versus $0.20 \pm$ $0.50 \mu \mathrm{g} / \mathrm{dL} ; P \leq 0.05)$. The anthropometric, biochemical and body composition (DXA) data of NW, NWO, and PreOB/OB groups, in accordance with the genotype polymorphism at positions -308 of the TNF- $\alpha$ gene promoter, were reported in Table 4.

Distinguishing population in 3 different groups we found $n$. $17 \mathrm{NW}$ subjects ( $26.3 \pm 6.6$ years, range $19-39) ; n$. $30 \mathrm{NWO}$ 
TABLE 2: Anthropometric and body composition parameters according to genotype.

\begin{tabular}{lcc}
\hline & Carrier $(-)$ & Carrier $(+)$ \\
Parameters & $n .70$ & $n .25$ \\
& Mean \pm SD & Mean \pm SD \\
\hline Height $(\mathrm{cm})$ & $161,58 \pm 6,51$ & $161,02 \pm 4,75$ \\
Weight $(\mathrm{Kg})$ & $69,14 \pm 16,69$ & $67,64 \pm 13,01$ \\
BMI $\left(\mathrm{Kg} / \mathrm{m}^{2}\right)$ & $26,38 \pm 5,62$ & $26,17 \pm 5,29$ \\
WC $(\mathrm{cm})$ & $78,74 \pm 12,42$ & $79,10 \pm 12,35$ \\
HC $(\mathrm{cm})$ & $100,93 \pm 14,81$ & $104,55 \pm 10,52$ \\
W/H & $0,79 \pm 0,11$ & $0,75 \pm 0,06$ \\
TBMD $\left(\mathrm{g} / \mathrm{cm}^{2}\right)$ & $1,16 \pm 0,09$ & $1,17 \pm 0,06$ \\
TBMC $(\mathrm{g})$ & $2491,88 \pm 405,41$ & $2506,52 \pm 261,07$ \\
PBF $(\%)$ & $39,01 \pm 9,57$ & $39,21 \pm 8,57$ \\
TBFat $(\mathrm{Kg})$ & $27,46 \pm 11,81$ & $27,15 \pm 10,13$ \\
TBLean $(\mathrm{Kg})$ & $38,17 \pm 7,09$ & $37,40 \pm 4,26$ \\
ASMMI $\left(\mathrm{kg} / \mathrm{m}^{2}\right)$ & $6,47 \pm 0,86$ & $6,48 \pm 0,79$ \\
\hline
\end{tabular}

Carrier (-): -308 TNF- $\alpha$ G/G genotype; carrier (+): -308 TNF- $\alpha$ A/G genotype; BMI: body mass index; WC: waist circumference; HC: hip circumference; TBMD: total bone mineral density; TBMC: total bone mineral content; PBF: percentage of total body fat mass; TBFat: total body fat mass; TBLean: total body lean mass; ASMMI: appendicular skeletal muscle mass index.

TABLE 3: Blood biochemical parameters and cardiovascular risk factors according to genotype.

\begin{tabular}{lcc}
\hline & Carrier $(-)$ & Carrier $(+)$ \\
Parameters & $n .70$ & $n .25$ \\
& Mean \pm SD & Mean \pm SD \\
\hline FG $(\mathrm{mg} / \mathrm{dL})$ & $91,33 \pm 7,33$ & $89,88 \pm 7,15$ \\
FI $(\mu \mathrm{U} / \mathrm{mL})$ & $7,98 \pm 4,64$ & $8,00 \pm 4,35$ \\
HOMA-IR & $3,35 \pm 2,05$ & $3,21 \pm 1,70$ \\
TC $(\mathrm{mg} / \mathrm{dL})$ & $203,44 \pm 41,45$ & $192,12 \pm 31,96$ \\
HDL-chol $(\mathrm{mg} / \mathrm{dL})$ & $65,16 \pm 15,66$ & $65,82 \pm 14,38$ \\
LDL-chol $(\mathrm{mg} / \mathrm{dL})$ & $116,18 \pm 35,68$ & $110,33 \pm 32,53$ \\
TG $(\mathrm{mg} / \mathrm{dL})$ & $96,12 \pm 39,75$ & $87,06 \pm 33,79$ \\
TC/HDL-chol ratio & $3,25 \pm 0,85$ & $3,03 \pm 0,77$ \\
LDL/HDL-chol ratio & $1,74 \pm 0,79$ & $1,71 \pm 0,74$ \\
Log TG/HDL-chol ratio & $1,58 \pm 0,84$ & $1,37 \pm 0,58$ \\
hs-CRP $(\mu \mathrm{d} / \mathrm{dL})$ & $0,73 \pm 1,78$ & $0,20 \pm 0,50^{*}$ \\
TNF- $\alpha(\mathrm{pg} / \mathrm{mL})$ & $26,42 \pm 15,33$ & $20,62 \pm 11,66$ \\
\hline
\end{tabular}

${ }^{*} P<0.05$.

Carrier (-): -308 TNF- $\alpha$ G/G genotype; carrier $(+)$ : -308 TNF- $\alpha$ A/G genotype; FG: fasting glucose; FI: fasting insulin; HOMA-IR: homeostasis model of assessment-insulin resistance; TC: total cholesterol; HDL-chol: HDL cholesterol; LDL-chol: LDL cholesterol; TG: triglycerides; hs-CRP: high-sensitivity C-reactive protein.

subjects (29.7 \pm 9.4 years; range $17-59) ; n .48$ PreOB/OB (38.4 \pm 12.8 years, range $17-59)$.

Significant differences between NW, NWO, and PreOB/OB subjects were observed. No significant differences in $\mathrm{HC}$ and $\mathrm{W} / \mathrm{H}$ ratio, lean arms, lean legs, and lean trunk were observed between the NWO and NW women, whereas
BMI, PBF, TBFat weight, and waist circumference were significantly different $(P<0.001)$.

As expected, body weight, $\mathrm{BMI}, \mathrm{HC}, \mathrm{WC}, \mathrm{W} / \mathrm{H}$ ratio, $\mathrm{PBF}$, TBLean, and lean legs were significantly different between the $\mathrm{PreOB} / \mathrm{OB}$ and NW groups.

PreOB/OB subjects with respect to NWO showed higher weight, BMI, WC, HC, W/H ratio, $\mathrm{PBF}$, and TBLean $(P<$ $0.001)$.

Respect to groups NW and NWO, PreOB/OB subjects showed higher amount of fat mass, evaluated as PBF $(P<$ $0.001)$ and TBFat $(P<0.001)$. Moreover, PreOB/OB subjects showed higher sarcopenic index with respect to other groups $(P<0.001)$.

In NW subjects no differences were observed between carrier (-) and carrier (+). However, significant inter and intragenotype differences between NW, NWO, and PreOB/ $\mathrm{OB}$ in all evaluated parameters were remarked $(P<0.001)$.

Carrier $(+)$ NWO subjects showed significantly higher HC with respect to carrier $(-)(P<0.001)$.

Among overall carrier (-), NWO showed significant differences in lean arms, lean legs, lean trunk, and TBLean with respect to NW and PreOB/OB $(P<0.001)$. However, these similar results have not been confirmed between carrier $(+)$; in fact there are differences in terms of lean mass, but they are not significant.

Among overall carrier $(+)$, PreOB/OB showed higher weight, BMI, WC, $\mathrm{HC}, \mathrm{PBF}$, and TBFat with respect to NW and NWO $(P 0.05)$ and higher ASMMI with respect to NW $(P$ 0.05), whereas NWO showed higher BMI, PBF, and TBFat with respect to NW (P 0.05).

Regarding sarcopenic index values, among NW, 4.21\% $(n=4)$ of them were sarcopenic $(50 \%$ were carrier $(-)$ and $50 \%$ carrier $(+))$; the same percentage was observed in NWO subjects (100\% carrier $(-))$. Moreover, in PreOB/OB, $2.10 \%$ of them were sarcopenic and all were carrier $(-)$.

Table 5 shows the biochemical parameters in study groups in accordance with genotype. No significant differences between NW and NWO were observed. With respect to NW and NWO, PreOB/OB subjects showed significantly higher levels of insulin ( $P$ 0.01), HOMA-IR $(P$ 0.01), total

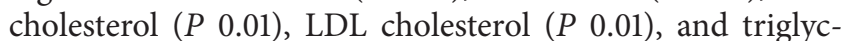
erides $(P 0.01)$ and lower levels of HDL cholesterol $(P 0.01)$.

Regarding atherogenic indices, $\mathrm{PreOB} / \mathrm{OB}$ showed higher

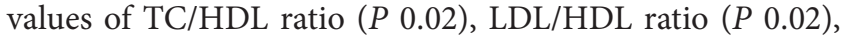

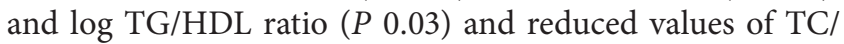
LDL ( $P$ 0.01) than NW and NWO groups. PreOB/OB subjects showed higher levels of PCR than other groups $(P 0.01)$. In PreOB/OB subjects we found slightly higher levels of TNF- $\alpha$ than NW and NWO subjects ( $P$ 0.01). PreOB/OB carrier $(+)$ genotype had significantly reduced levels of TNF$\alpha$ with respect to carrier $(-)(P 0.03)$. No statistical differences of TNF- $\alpha$ circulating levels between NW and NWO were observed.

\section{Discussion}

Obesity plays relevant pathophysiological role in the development of health problems, arising as result of complex interaction of genetic, nutritional, and metabolic factors [32]. 


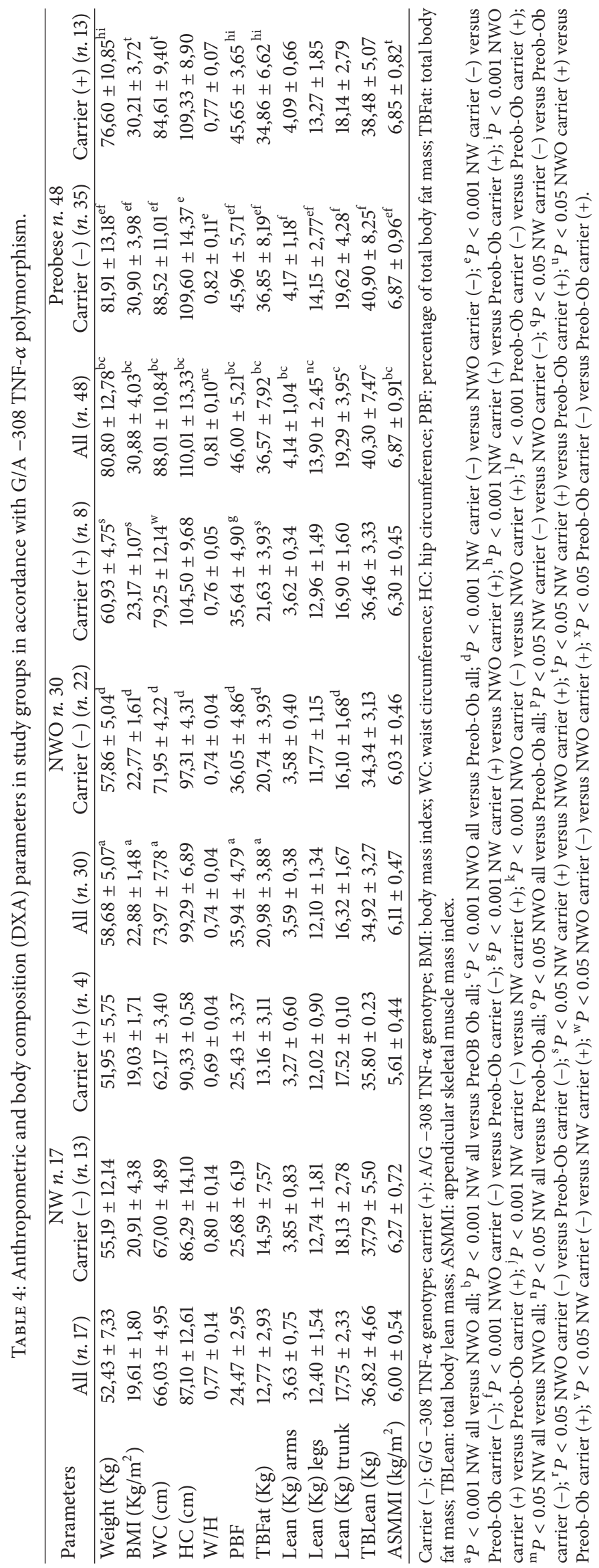




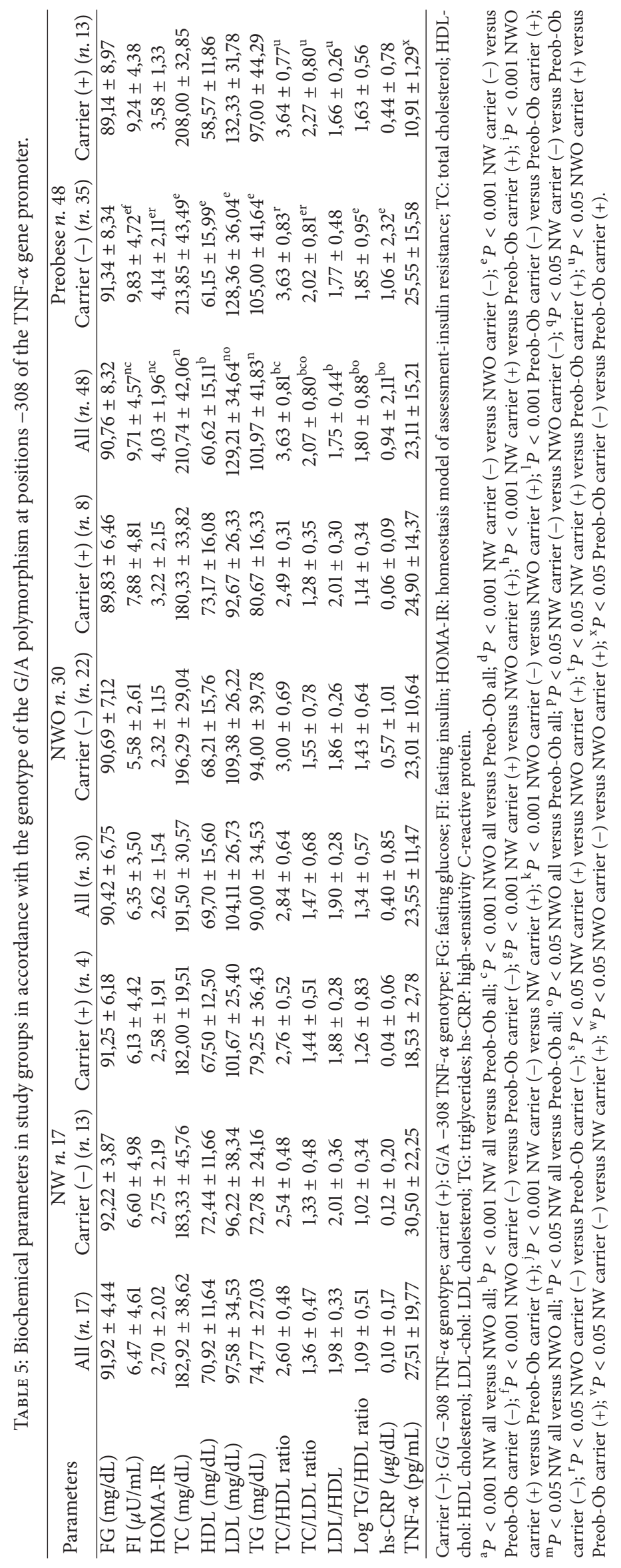


Adipokines and myokines appear to be involved, respectively, in autocrine/paracrine interactions within adipose tissue and muscle, involved in the endocrine bidirectional cross-talk between these tissues [33]. Use of adiposity measures rather than BMI could be a better cardiovascular risk predictor and obesity-related diseases $[33,34]$.

Our results confirm these recent data, highlighting the problem of obesity misclassification by BMI, especially in women subjects. We confirmed that BMI significantly underestimates prevalence of obesity when compared to DXA direct measurement of percent body fat. The majority of women classified as normal by BMI were found to be obese by PBF [35]. In our study, according to PBF classification, the overall percentage of obese women was $82.10 \%$, with error percentage between the two classifications relevant $(30.39 \%)$ $(P<0.005)$. None of the subjects classified as obese by BMI were sarcopenic; however when all women were classified by DXA, the $7.69 \%$ of them presented sarcopenic obesity. Characterization of sarcopenic obesity and the ASMMI revealed that $9.85 \%$ of the eutrophic subjects determined by BMI exhibited sarcopenic obesity, while none of the obese was sarcopenic. Moreover, by DXA the $23.53 \%$ were eutrophic and sarcopenic subjects.

Several genetic studies were performed in order to discover the genes involved in the development of obesity susceptibility, and more than 300 genes have been putatively identified [4]. Certain single nucleotide polymorhisms (SNPs), occurring within the promoter region of a large number of genes, influence the transcriptional activity of genes, resulting in intraindividual differences in the amount of protein produced by the gene.

TNF- $\alpha$ has a direct paracrine function in adipose tissue, reducing fat mass through stimulation of lipolysis and reduction of LPL expression and activity [36].

In human skeletal muscle and adipose tissue, TNF$\alpha$ messenger RNA levels were positively correlated with downregulation of the GLUT4 glucose transporter, body mass index (BMI), fat mass, and serum levels of insulin and inversely correlated with lipoprotein lipase activity [37].

The promoter region of the TNF- $\alpha$ gene contains several single nucleotide polymorphisms (SNPs), such as G/A -238, $\mathrm{G} / \mathrm{A}-308$, and $\mathrm{C} / \mathrm{A}-863$, altering transcriptional activity of TNF- $\alpha$ mRNA [38]. The functional role of the G/A -308 TNF- $\alpha$ polymorphism is currently unclear.

In the present study, the genetic variation of the G/A -308 polymorphism in the TNF- $\alpha$ promoter gene was firstly analyzed in NWO syndrome [15], comparing NW and PreOB/OB subjects.

Our data partially match the previously published data $[16,23-25]$. In our subjects BMI, weight, WC, and TBFat were not different across genotypes.

Several studies showed that G/A polymorphism is not useful to promote obesity or metabolic abnormalities [37]. In Italian and Danish population, G/A polymorphism is unlikely to play an important role in the development of obesity and its related metabolic abnormalities [39, 40].

The allele A was associated with obesity, in individuals between 50 and 60 years [41]. Our result obtained in a young population confirmed the previous data $[29,42]$. In Spanish obese subjects (70\% females) any differences of anthropometric, metabolic profile and adipokines levels in accordance with G/A -308 TNF- $\alpha$ polymorphism were found. The conflicting data can be due to differences in methodologies of study, suggesting that obesity could be related to this polymorphism after the fifth decade of life.

In our study, no differences in allele frequency of G/A -308 TNF- $\alpha$ polymorphism were observed in NW, NWO, and PreOB/OB subjects, as well as no differences in serum levels of TNF- $\alpha$ cytokine in the study groups with the exception of PreOB/OB carrier (+).

Moreover, HOMA-IR values were significantly higher in all and PreOB/OB carrier (-) subjects compared to NW and NWO women. However, no differences were observed between the HOMA-IR of NW and NWO women.

One of the aftermath of insulin resistance is sarcopenia. In this study, we found significant associations with TBLean and the TNF- $\alpha$ gene polymorphism.

To understand the role of the proinflammatory cytokines in skeletal muscle differentiation, which appear to be controversial $[43,44]$, it is important to clarify the several mechanisms of TNF- $\alpha$.

TNF- $\alpha$ promotes the activation of transcription factors such as nuclear factor $-\kappa \mathrm{B}(\mathrm{NF}-\kappa \mathrm{B})$ and $\mathrm{AP}-1$ (activator protein-1).

Transforming growth factor- $\beta$-activated kinase-1 (TAK1 ) is critical for TNF- $\alpha$-induced activation of NF- $\kappa \mathrm{B}$ and mitogen-activated protein kinases (MAPK) signaling pathways, especially p38 $[45,46]$. TAK- 1 connects TNF- $\alpha$ to activin signaling, explaining how these cytokines can inhibit myogenesis, establishing the physiologic relevance of this pathway in the impaired regeneration observed in sarcopenia [47]. The induction of activin A secretion downstream of cytokine pathway stimulation suggests a mechanism explaining how cytokines alter muscle differentiation, because it is well established that TGF- $\beta$ family members such as myostatin and Activin A can block myoblast differentiation [48]. Moreover, TNF- $\alpha$ drastically increases the production of matrix metalloproteinase (MMP)-9, leading to skeletal muscle tissue loss in various pathological conditions [49].

This is the first study that shows the importance of the TNF- $\alpha$ gene polymorphism to TBLean variation in NWO syndrome, representing our pilot effort to further studies.

Finally, we mention some limitations of the study: (1) our study was performed only in adult female subjects, excluding elderlies [50]; (2) the number of included subjects was relatively low; thus validation of the results in larger and independent cohorts is recommended to confirm our hypothesis of etiology of sarcopenic obesity susceptibility, depending on body composition, BMI, and TNF- $\alpha$ gene polymorphism and to exclude the risk of false negative findings.

These findings may be used to develop a prediction model for sarcopenia; if confirmed in a larger population, it could represent a new management approach for the correct diagnosis and therapeutic choice in the prediction and prevention of sarcopenic obesity. 


\section{Conflict of Interests}

The authors declared that they have no conflict of interests.

\section{Acknowledgment}

This study was supported in part by grants from Ministero Politiche Agricole Alimentari e Forestali (D. M.; 20099 23.12.2009 and D. M.; 2017188 03/24/2011).

\section{References}

[1] A. Coin, S. Sarti, and E. Ruggiero, "Prevalence of sarcopenia based on different diagnostic criteria using DEXA and appendicular skeletal muscle mass reference values in an Italian population aged 20 to 80," Journal of the American Medical Directors Association, 2013.

[2] F. Gloria-Bottini, V. Cervelli, G. F. Giarrizzo, R. Martinoli, L. Di Renzo, and A. De Lorenzo, "Sex differences in body fat parameters from the early reproductive to the postreproductive period of life: a multivariate analysis," Human Biology, vol. 79, no. 4, pp. 373-379, 2007.

[3] G. Frühbeck, "Hunting for new pieces to the complex puzzle of obesity," Proceedings of the Nutrition Society, vol. 65, pp. 329347, 2006.

[4] T. Rankinen, A. Zuberi, Y. C. Chagnon et al., "The human obesity gene map: the 2005 update," Obesity, vol. 14, no. 4, pp. 529-644, 2006.

[5] A. J. Cruz-Jentoft, J. P. Baeyens, J. M. Bauer et al., "Sarcopenia: European consensus on definition and diagnosis," Age and Ageing, vol. 39, no. 4, Article ID afq034, pp. 412-423, 2010.

[6] A. O. Silva, M. G. Karnikowski, S. S. Funghetto et al., "Association of body composition with sarcopenic obesity in elderly women," International Journal of General Medicine, vol. 6, pp. 25-29, 2013.

[7] A. de Lorenzo, L. di Renzo, A. Puja, P. Saccucci, F. GloriaBottini, and E. Bottini, "A study of acid phosphatase locus 1 in women with high fat content and normal body mass index," Metabolism, vol. 58, no. 3, pp. 351-354, 2009.

[8] A. Romero-Corral, V. K. Somers, J. Sierra-Johnson et al., "Accuracy of body mass index in diagnosing obesity in the adult general population," International Journal of Obesity, vol. 32, no. 6, pp. 959-966, 2008.

[9] World Health Organization, "Physical status: the use and interpretation of anthropometry. Report of a WHO Expert Committee," World Health Organization Technical Reports Series, vol. 854, pp. 1-452, 1995.

[10] J. Y. Chung, H. T. Kang, D. C. Lee, H. R. Lee, and Y. J. Lee, "Body composition and its association with cardiometabolic risk factors in the elderly: a focus on sarcopenic obesity," Archives of Gerontology and Geriatrics, vol. 56, no. 1, pp. 270-278, 2013.

[11] M. di Monaco, F. Vallero, R. Di Monaco, and R. Tappero, "Prevalence of sarcopenia and its association with osteoporosis in 313 older women following a hip fracture," Archives of Gerontology and Geriatrics, vol. 52, no. 1, pp. 71-74, 2011.

[12] A. de Lorenzo, P. Deurenberg, M. Pietrantuono, N. Di Daniele, V. Cervelli, and A. Andreoli, "How fat is obese?" Acta Diabetologica, vol. 40, no. 1, pp. S254-S257, 2003.

[13] F.-C. Hsu, L. Lenchik, B. J. Nicklas et al., "Heritability of body composition measured by DXA in the Diabetes Heart Study," Obesity Research, vol. 13, no. 2, pp. 312-319, 2005.
[14] A. de Lorenzo, A. Bianchi, P. Maroni et al., "Adiposity rather than BMI determines metabolic risk," International Journal of Cardiology, vol. 166, no. 1, pp. 111-117, 2011.

[15] A. De Lorenzo, R. Martinoli, F. Vaia, and L. Di Renzo, "Normal weight obese (NWO) women: an evaluation of a candidate new syndrome," Nutrition, Metabolism and Cardiovascular Diseases, vol. 16, no. 8, pp. 513-523, 2006.

[16] A. De Lorenzo, V. Del Gobbo, M. G. Premrov, M. Bigioni, F. Galvano, and L. Di Renzo, "Normal-weight obese syndrome: early inflammation?" American Journal of Clinical Nutrition, vol. 85, no. 1, pp. 40-45, 2007.

[17] L. Di Renzo, F. Galvano, C. Orlandi et al., "Oxidative stress in normal-weight obese syndrome," Obesity, vol. 18, no. 11, pp. 2125-2130, 2010.

[18] L. Di Renzo, V. Del Gobbo, M. Bigioni, M. G. Premrov, R. Cianci, and A. De Lorenzo, "Body composition analyses in normal weight obese women," European Review for Medical and Pharmacological Sciences, vol. 10, no. 4, pp. 191-196, 2006.

[19] L. Di Renzo, A. Noce, S. De Angelis et al., "Anti-inflammatory effects of combined treatment with acetyl salicylic acid and atorvastatin in haemodialysis patients affected by Normal Weight Obese syndrome," Pharmacological Research, vol. 57, no. 2, pp. 93-99, 2008.

[20] P. Marques-Vidal, A. Pécoud, D. Hayoz et al., "Prevalence of normal weight obesity in Switzerland: effect of various definitions," European Journal of Nutrition, vol. 47, no. 5, pp. 251-257, 2008.

[21] P. Marques-Vidal, A. Pécoud, D. Hayoz et al., "Normal weight obesity: relationship with lipids, glycaemic status, liver enzymes and inflammation," Nutrition, Metabolism and Cardiovascular Diseases, vol. 20, no. 9, pp. 669-675, 2010.

[22] A. Romero-Corral, V. K. Somers, J. Sierra-Johnson et al., "Normal weight obesity: a risk factor for cardiometabolic dysregulation and cardiovascular mortality," European Heart Journal, vol. 31, no. 6, pp. 737-746, 2010.

[23] L. Di Renzo, M. Bigioni, F. G. Bottini et al., "Normal weight obese syndrome: role of single nucleotide polymorphism of IL$15 \mathrm{R} \alpha$ and MTHFR 677C $\rightarrow$ T genes in the relationship between body composition and resting metabolic rate," European Review for Medical and Pharmacological Sciences, vol. 10, no. 5, pp. 235245, 2006.

[24] L. Di Renzo, M. Bigioni, V. Del Gobbo et al., "Interleukin-1 (IL1) receptor antagonist gene polymorphism in normal weight obese syndrome: relationship to body composition and IL-1 $\alpha$ and $\beta$ plasma levels," Pharmacological Research, vol. 55, no. 2, pp. 131-138, 2007.

[25] L. Di Renzo, A. Bertoli, M. Bigioni et al., "Body composition and -174G/C interleukin-6 promoter gene polymorphism: association with progression of insulin resistance in normal weight obese syndrome," Current Pharmaceutical Design, vol. 14, no. 26, pp. 2699-2706, 2008.

[26] J. M. Argilés, J. López-Soriano, V. Almendro, S. Busquets, and F. J. López-Soriano, "Cross-talk between skeletal muscle and adipose tissue: a link with obesity?" Medicinal Research Reviews, vol. 25, no. 1, pp. 49-65, 2005.

[27] G. Frühbeck, J. Gómez-Ambrosi, F. J. Muruzábal et al., “The adipocyte: a model for integration of endocrine and metabolic signaling in energy metabolism regulation," American Journal of Physiology: Endocrinology and Metabolism, vol. 280, pp. E827E847, 2001.

[28] G. E. Nedwin, S. L. Naylor, A. Y. Sakaguchi et al., "Human lymphotoxin and tumor necrosis factor genes: structure, homology 
and chromosomal localization," Nucleic Acids Research, vol. 13, no. 17 , pp. 6361-6373, 1985.

[29] A. G. Wilson, J. A. Symons, T. L. Mcdowell, H. O. Mcdevitt, and G. W. Duff, "Effects of a polymorphism in the human tumor necrosis factor $\alpha$ promoter on transcriptional activation," Proceedings of the National Academy of Sciences of the United States of America, vol. 94, no. 7, pp. 3195-3199, 1997.

[30] V. Cervelli, L. Di Renzo, M. Grimaldi et al., "Dual Energy XRay Absorptiometry in pre-obese/obese women undergoing reduction mammaplasty," Journal of Plastic, Reconstructive and Aesthetic Surgery, vol. 62, no. 6, pp. e187-e189, 2009.

[31] J. M. Fernández-Real, C. Gutierrez, W. Ricart et al., "The TNF$\alpha$ gene Nco I polymorphism influences the relationship among insulin resistance, percent body fat, and increased serum leptin levels," Diabetes, vol. 46, no. 9, pp. 1468-1472, 1997.

[32] A. R. Shuldiner, "Obesity genes and gene-environment-behavior interactions: recommendations for a way forward," Obesity, vol. 16, no. 3, pp. S79-S81, 2008.

[33] N. R. Shah and E. R. Braverman, "Measuring adiposity in patients: the utility of body mass index (BMI), percent body fat, and leptin," PLoS ONE, vol. 7, no. 4, Article ID e33308, 2012.

[34] D. Wormser, S. Kaptoge, E. Di Angelantonio et al., "Separate and combined associations of body-mass index and abdominal adiposity with cardiovascular disease: collaborative analysis of 58 prospective studies," The Lancet, vol. 377, no. 9771, pp. 10851095, 2011.

[35] F. B. Madeira, A. A. Silva, and H. F. Veloso, "Normal weight obesity is associated with metabolic syndrome and insulin resistance in young adults from a middle-income country," PLoS ONE, vol. 8, no. 3, Article ID e60673, 2013.

[36] J. M. Argilés, J. López-Soriano, S. Busquets, and F. J. LópezSoriano, "Journey from cachexia to obesity by TNF," FASEB Journal, vol. 11, no. 10, pp. 743-751, 1997.

[37] R. Feinstein, H. Kanety, M. Z. Papa, B. Lunenfeld, and A. Karasik, "Tumor necrosis factor- $\alpha$ suppresses insulin-induced tyrosine phosphorylation of insulin receptor and its substrates," Journal of Biological Chemistry, vol. 268, no. 35, pp. 2605526058, 1993.

[38] M. Hedayati, K. Sharifi, F. Rostami, M. S. Daneshpour, M. Zarif Yeganeh, and F. Azizi, "Association between TNF- $\alpha$ promoter G-308A and G-238A polymorphisms and obesity," Molecular Biology Reports, vol. 39, no. 2, pp. 825-829, 2012.

[39] S. Romeo, F. Sentinelli, F. Capici et al., "The G-308A variant of the Tumor Necrosis Factor- $\alpha$ (TNF- $\alpha$ ) gene is not associated with obesity, insulin resistance and body fat distribution," $B M C$ Medical Genetics, vol. 2, article 10, 2001.

[40] S. K. Rasmussen, S. A. Urhammer, J. N. Jensen, T. Hansen, K. Borch-Johnsen, and O. Pedersen, "The -238 and $-308 \mathrm{G} \rightarrow \mathrm{A}$ polymorphisms of the tumor necrosis factor $\alpha$ gene promotor are not associated with features of the insulin resistance syndrome or altered birth weight in Danish Caucasians," Journal of Clinical Endocrinology and Metabolism, vol. 85, no. 4, pp. 1731$1734,2000$.

[41] S. C. Sookoian, C. González, and C. J. Pirola, "Meta-analysis on the G308A TNF alpha gene variant and phenotypes associated with Metaboic sindrome," Obesity Research, vol. 13, pp. 21222130, 2005.

[42] D. A. de Luis, R. Aller, O. Izaola et al., "Allelic frequency of G380A polymorphism of tumor necrosis factor alpha gene and relation with cardiovascular risk factors and adipocytokines in obese patients," Nutricion Hospitalaria, vol. 26, no. 4, pp. 711$715,2011$.
[43] S.-E. Chen, B. Jin, and Y.-P. Li, “TNF- $\alpha$ regulates myogenesis and muscle regeneration by activating p38 MAPK," American Journal of Physiology: Cell Physiology, vol. 292, no. 5, pp. C1660C1671, 2007.

[44] D. C. Guttridge, M. W. Mayo, L. V. Madrid, C.-Y. Wang, and J. Baldwin A.S., "NF- $\kappa$ B-induced loss of MyoD messenger RNA: possible role in muscle decay and cachexia," Science, vol. 289, no. 5488, pp. 2363-2365, 2000.

[45] A. Adhikari, M. Xu, and Z. J. Chen, "Ubiquitin-mediated activation of TAK1 and IKK," Oncogene, vol. 26, no. 22, pp. 32143226, 2007.

[46] Y. Li, B.-H. Jiang, W. Y. Ensign Jr., P. K. Vogt, and J. Han, "Myogenic differentiation requires signalling through both phosphatidylinositol 3-kinase and p38 MAP kinase," Cellular Signalling, vol. 12, no. 11-12, pp. 751-757, 2000.

[47] A. U. Trendelenburg, A. Meyer, C. Jacobi et al., “TAK-1/p38/ nNF B signaling inhibits myoblast differentiation by increasing levels of Activin A," Skeletal Muscle, vol. 2, no. 1, article 3, 2012.

[48] H. D. Kollias, R. L. S. Perry, T. Miyake, A. Aziz, and J. C. McDermott, "Smad7 promotes and enhances skeletal muscle differentiation," Molecular and Cellular Biology, vol. 26, no. 16, pp. 6248-6260, 2006.

[49] A. K. Srivastava, X. Qin, N. Wedhas et al., "Tumor necrosis factor-\|augments matrix metalloproteinase-9 production in skeletal muscle cells through the activation of transforming growth factor- $\beta$-activated kinase 1 (TAK1)-dependent signaling pathway," Journal of Biological Chemistry, vol. 282, no. 48, pp. 35113-35124, 2007.

[50] R. Roubenoff, "Catabolism of aging: is it an inflammatory process?" Current Opinion in Clinical Nutrition and Metabolic Care, vol. 6, no. 3, pp. 295-299, 2003. 


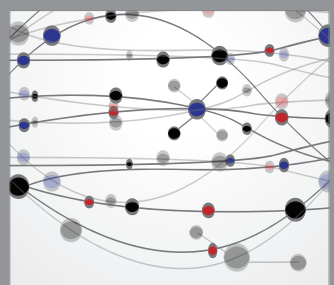

The Scientific World Journal
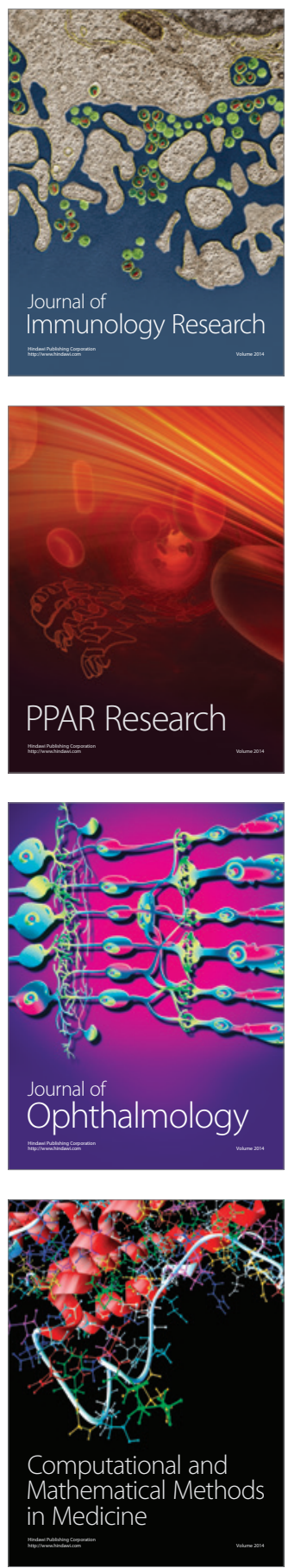

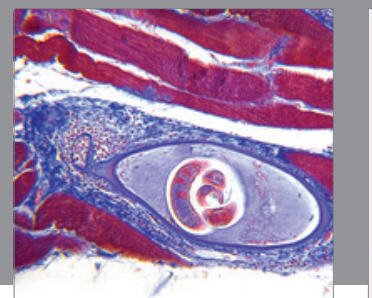

Gastroenterology

Research and Practice
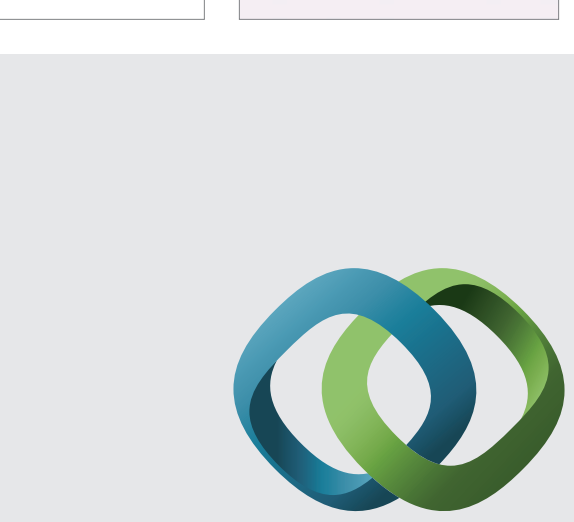

\section{Hindawi}

Submit your manuscripts at

http://www.hindawi.com
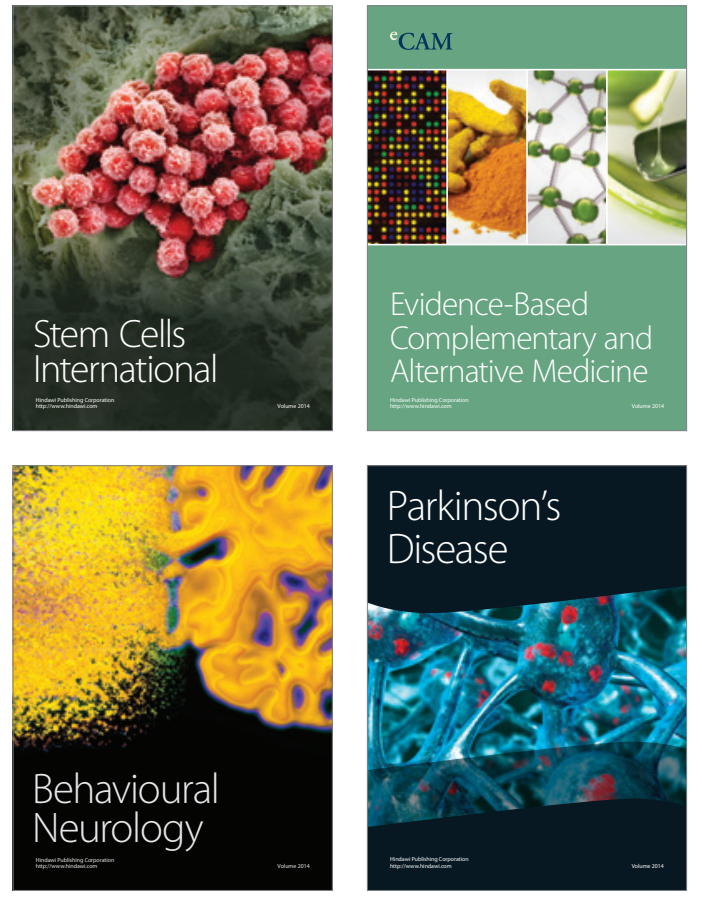
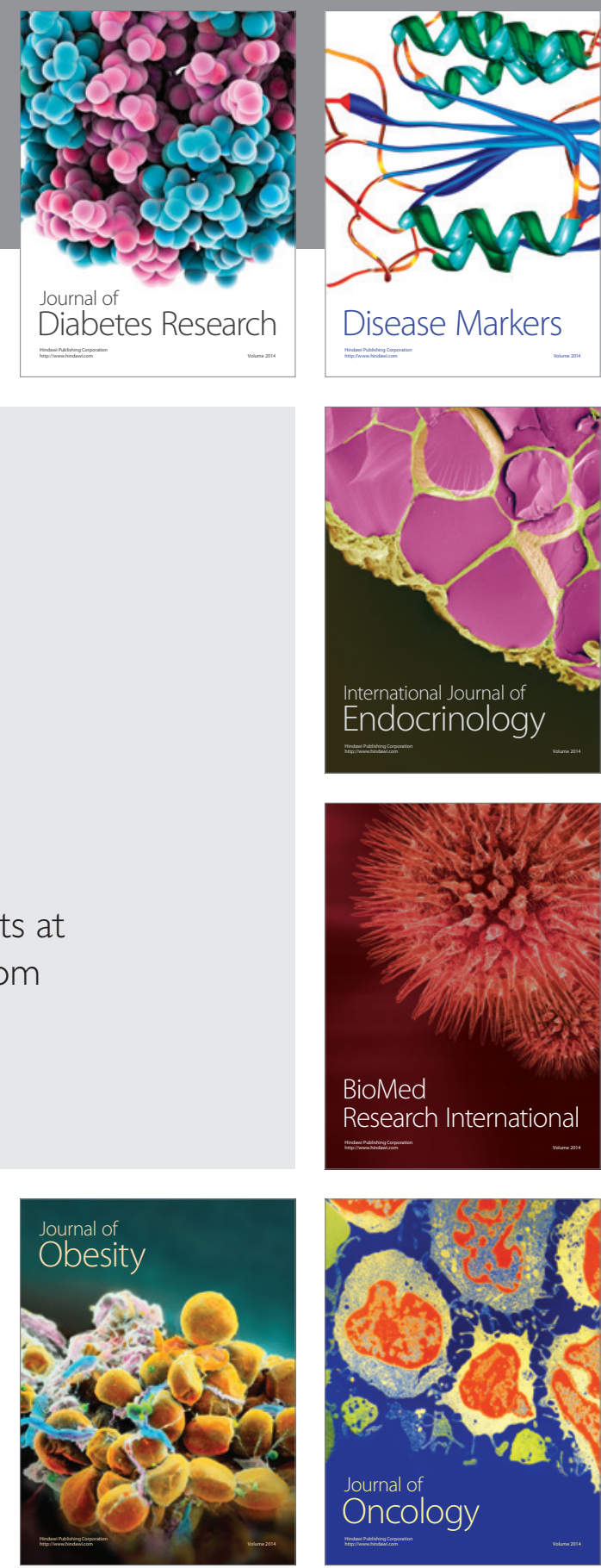

Disease Markers
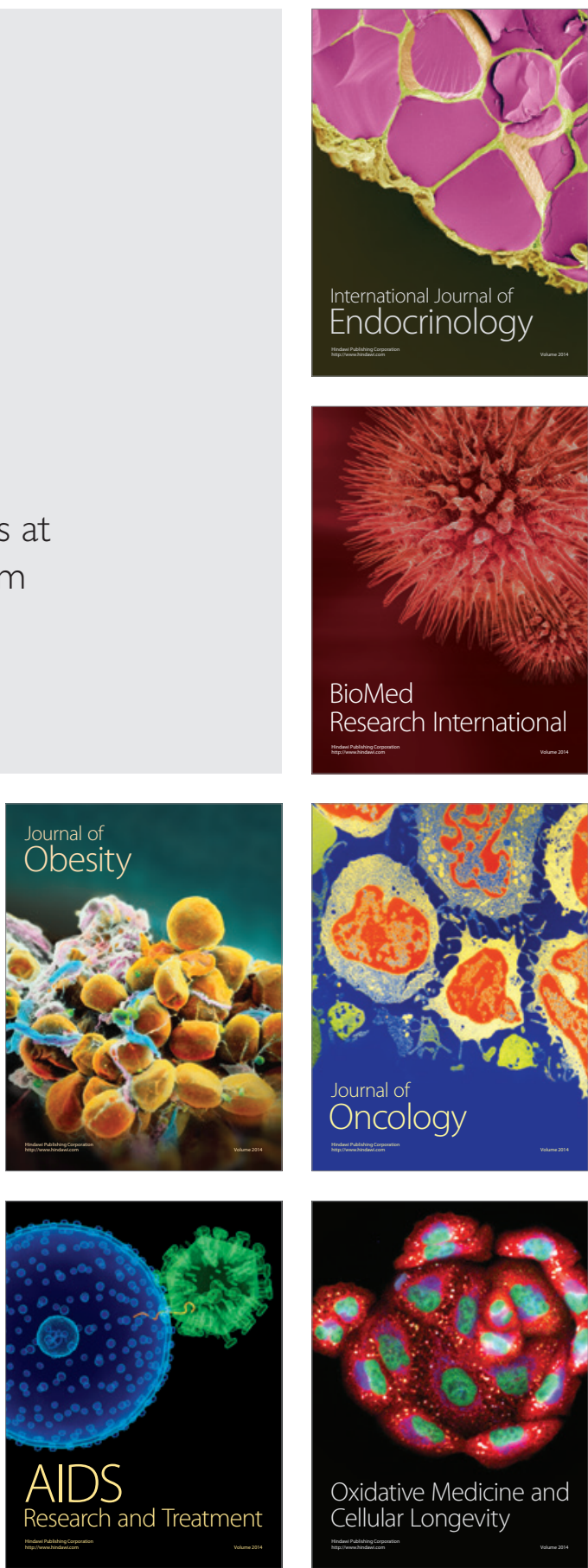